\title{
NOVO CONSTITUCIONALISMO LATINO AMERICANO E O RESPEITO AOS POVOS ORIGINÁRIOS: A QUESTÃO DOS TERRITÓRIOS INDÍGENAS NO ESTADO PLURINACIONAL DA BOLÍVIA
}

\section{THE NEW ERA OF LATIN-AMERICAN CONSTITUTIONALISM AND THE INDIGENOUS GROUPS: THE LAW PROVISIONS OF THE PLURINATIONAL STATE OF BOLÍVIA CONSTITUTION TO THE INDIGENOUS TERRITORIES.}

\author{
Anna Carolina Cunha Pinto* \\ Cecília Bojarski Pires**
}

\begin{abstract}
Resumo: O presente artigo pretende analisar os dispositivos legais constantes ao ordenamento jurídico do Estado Plurinacional da Bolívia que regulamentam o tratamento dado aos territórios dos povos indígenas originários. Como aporte para a referida análise discorreremos sobre aspectos relativos à colonização que reforçaram e perpetuaram por anos a ideia de que os povos originários consistiam em não pessoas e que, assim, estavam excluídas do Direito, compreensão que começou a ser mitigada com o advento da Constituição Mexicana de 1917 e de outras que, à seu exemplo, romperam com o viés conservador atentando-se mais para questões sociais que, no entanto, eram insuficientes no tocante aos direitos dos indígenas $A$ nova fase do constitucionalismo latino americano contempla, especialmente por intermédio de Bolívia e Equador, países que representam o constitucionalismo plurinacional, além de grande atenção com os direitos indígenas, a incorporação de seus conhecimentos e de sua cosmovisão nesse processo.
\end{abstract}

Palavras-chave: Povos indígenas. Terra indígena. Direito Constitucional. Direitos Humanos. América Latina.

Abstract: The main purpose of this article is to analyse the law provisions of the Plurinational State of Bolivia Constitution given to the indigenous territories. In this context, we will discuss points related to colonization process that reinforced and perpetuated the wrong idea that the indigenous people are non-people. In consequence, they were excluded for years from the protection of the law. However, the Plurinational State of Bolívia Constitution has broken with the previous conservative model and brought a new era of Latin-American constitutionalism, marked by the recognition of the indigenous as subjects of Law and as human person with a specific worldview.

Keywords:Indigenous People. Indigenous Land. Constitutional Law. Human Rights. LatinAmerica.

\footnotetext{
* Mestre em Ciências Jurídicas e Sociais pelo Programa de Pós Graduação em Sociologia e Direito da Universidade Federal Fluminense (PPGSD/ UFF), tendo integrado a linha de pesquisa de Direitos Humanos, Governança e Poder. E-mail: annacarolinapinto@id.uff.br

${ }^{* *}$ Professora de Direito Civil da UNESA. Mestre em Direito Constitucional pelo PPGDC/UFF. E-mail: ceciliapires@gmail.com
} 


\section{INTRODUÇÃO}

As sociedades indígenas americanas, notadamente as fixadas na América Latina, sejam as ditas de cultura primitiva ou mesmo as classificadas como de média e alta cultura têm seus costumes, suas terras, seus ritos e crenças, mas foram massacradas e subjugadas ao longo da história.

O início do "derramamento de sangue e lágrimas" se deu em nome do processo de conquista e colonização levada a cabo pelos europeus. (GALEANO, 2004, p. 49).

O modus operandi adotado refletia o espírito de uma Europa colonialista e mercantil que buscava a constituição de um mercado mundial através da associação de interesses privados variados com os interesses públicos das Monarquias Nacionais que, não raro, encontravam-se também vinculados à Igreja:

Associação entre os interesses privados de diversos tipos (de comerciantes, de aventureiros em busca de riqueza e posição de nobres com elevados cargos burocráticos) e interesses públicos (as Monarquias Nacionais), a cujo aparato com frequência se associava a Igreja. (AQUINO; LEMOS; LOPES, 2005, p. 70-71).

Ao chegarem no chamado "Novo Mundo" os conquistadores se depararam com um povo que classificaram, do alto de sua superioridade, como "selvagem", "bárbaro", "desprovido de alma" e "similar aos animais", que desconhecia as estruturas políticas nos moldes europeus, que cultuava a natureza e diversos deuses, em que predominavam regimes de comunidade primitiva e em que era desconhecida a propriedade privada da terra e o trabalho era realizado de maneira coletiva.

$O$ etnocentrismo reinante na mentalidade europeia, o choque cultural e a incapacidade de entender, aceitar e conviver com aquilo que é diferente, notadamente no que diz respeito ao culto à natureza e a falta de um modelo social, jurídico e político, "cegou" os colonizadores e legitimou a adoção de um processo civilizatório nos moldes europeus, ou seja, imposto sob o falso pretexto da busca de um "bem maior".

A visão que os europeus tinham da Europa e deles mesmos nos parece bem delineada na observação feita por Priori, na obra de Myriam Mota e Patrícia Braick, que destacam que a figura que representava a Europa era costumeiramente 
apresentada sentada ou de pé, trajando vestidos e adornada por elementos como coroa, cetro e armas. Por outro lado, a América era apresentada quase sempre deitada, despida, enfeitada por penas e portando arco e flecha ou frutos: "Quase sempre deitada, com a cabeça ornada de penas, trazendo sobre o corpo nu apenas um saiote e carregando um arco e flecha e uma maçã, tendo aos pés um tatu ou um jacaré, apresenta-se a América" (MOTA; BRAICK, 2002, p. 142).

Sendo assim, por serem "selvagens" e "inferiores aos europeus", os índios deviam ser tratados não como pessoas, mas sim como "coisas", como "objetos" e como meio para a realização de um fim.

Galeano (2004) em diversas passagens de As veias abertas da América Latina descreve o que intitula de "justificativas ideológicas" para o tratamento degradante despendido aos indígenas. Entre elas destacamos o fato de os europeus acreditarem que suas atitudes constituíam, bem da verdade, um ato de salvação, de caridade ou uma razão de fé; a crença de que os corpos indígenas resistiam mais aos esforços físicos do que os corpos dos animais, fato que justificava a exploração; a ideia de que o trabalho pesado era o "melhor remédio" para curar a "maldade natural" dos indígenas e de que "seus pecados e idolatrias constituíam uma ofensa a Deus", sendo a exploração uma espécie de castigo divino; o fato de que não tinham "nenhuma atividade de alma"; a certeza de que eram "homens degradados" e, por fim, a crença de que os índios deveriam ser gratos aos espanhóis, bons homens que, através da exploração e da matança, Ihes davam a chance de redimirem-se de seus pecados.Nesse contexto, os processos de conquista e colonização foram "justificadamente" sangrentos, podendo ser enquadrados como comportamentos etnocidas.

Com o avançar do tempo, ainda que de forma estritamente formal, já que na América a lei "se acatava, mas não se cumpria" (GALEANO, 2004, p. 51) por razões menos nobres do que a preocupação com a vida dos indígenas e atendendo aos interesses públicos e da igreja, passou a ser expressamente proibido que os direitos dos nativos fossem violados. O Papa Paulo III, por meio de uma bula papal, reconheceu que os índios tinham direito à liberdade, ao domínio de seus bens, e que não deveriam ser reduzidos a servidão. 
No entanto, não nos parece que tenha ocorrido um movimento no sentido de reconhecer que os indígenas poderiam praticar sua cultura e fé e assumir sua identidade étnica, uma vez que tal bula trouxe também a ideia de que os índios deveriam seguir a fé de Cristo e o exemplo da boa vida. Acertada é a visão de que a bula do Papa Paulo III serviu mais para "reivindicar a jurisdição da igreja sobre as almas dos indígenas." (CUNHA, 2012, p. 34). Afinal, a descoberta de um mundo novo e de um novo povo traz novas questões que, em nome dos interesses e necessidades ocidentais, precisam ser tratadas, passando a ser problema crucial inserir a nova realidade na "economia divina, o que implica inseri-la na genealogia dos povos." (CUNHA, 2012, p. 35).

De acordo com Gargarella (2014), com o avançar da história, as constituições latino-americanas que adentraram o século XX eram baseadas nas ideias do século anterior e fruto de um constitucionalismo de fusão e de cunho liberal-conservador. Eram constituições elitistas, não plurais e trataram de garantir para as classes detentoras de poder os privilégios de sempre.

Nesse cenário, de acordo com Brandão (2015, p. 1), houve "uma confluência entre a herança colonial ibérica burocrático-centralizadora de um lado e, de outro, uma tradição liberal - individualista utilizada a serviço dos detentores do poder".

A partir de 1917, muito inspiradas no modelo Mexicano, as "constituições latino-americanas começaram a agregar novas preocupações sociais." (GARGARELLA, 2014, p. 12). No entanto, de acordo com Yrigoyen Fajardo (2011) tais preocupações não foram suficientes para o reconhecimento de uma identidade dos povos indígenas, tendo assumido uma postura mais integracionista e até paternalista do que de aceitação da existência de uma identidade indígena, não chegando a produzir a admissão explícita de um pluralismo jurídico.

O fim da década de 80, por sua vez, trouxe para a América Latina uma "nova onda de reformas constitucionais" (GARGARELLA, 2014, p. 13) em resposta ao fim dos governos militares e as reformas neoliberais sofridas. De maneira geral, as novas e atuais constituições dos países latino-americanos são mais participativas e sociais, bem como pluriculturais, afastando-se da visão integracionista, reconhecendo a identidade indígena e também garantindo a tais povos maior proteção. 
Nesse contexto evolutivo que tende ao reconhecimento dos direitos dos povos indígenas, o presente artigo pretende analisar 0 tratamento normativo constitucional dado à questão das terras originariamente ocupadas pelos povos indígenas na América Latina, especificamente na Bolívia.

A escolha pela análise de tal ponto se deu em virtude de assumir o território grande importância dentro da cosmovisão indígena e também na estrutura das sociedades coloniais e pós-coloniais.

A eleição do país a ser analisado se deu, inicialmente, com base nos estudos elaborados por Barrié (2003), que classificou os países latino-americanos em 3 grupos de acordo com a recente adesão aos direitos indígenas no âmbito de suas constituições: a) países que não possuem preocupação com as minorias étnicas, notadamente indígenas, em suas constituições, sendo eles: Belize, Chile, Guiana Francesa, Suriname e Uruguai; b) países que outorgam alguma proteção pontual aos grupos étnicos, porém tal proteção se dá dentro de um marco legal incompleto ou pouco articulado, sendo eles: Costa Rica, El Salvador, Guiana e Honduras; e c) países nos quais há extenso tratamento constitucional em relação aos grupos étnicos, ainda que a amplitude de tais direitos não seja a mesma, sendo eles: Argentina, Bolívia, Brasil, Colômbia, Equador, Guatemala, México, Nicarágua, Panamá, Paraguai, Peru e Venezuela.

Na sequência, descartamos os grupos ' $a$ ' $e$ ' $b$ ', por serem menos produtivos para o estudo, e nos detivemos no grupo ' $c$ ', por ser o que contém países que mais fazem referência aos direitos indígenas.

A partir de então, nossa escolha se deu com base nos estudos de Yrigoyen Fajardo (2011) que, ao dividir a nova fase do constitucionalismo na América Latina, elegeu os países Bolívia e Equador como representantes do chamado constitucionalismo plurinacional, que não só realizaram uma "ampla positivação dos direitos indígenas", como também internalizaram o conhecimento e a cosmovisão de tais povos nesse processo. Finalmente, elegemos a Bolívia como objeto de estudo por ser o país que conta com a Constituição mais atual, datada de 2009.

Destacamos que não pretendemos por meio deste artigo esgotar o tema, mas constatar, sem a análise de casos concretos, de que modo e em qual medida se 
dá a proteção normativa constitucional dos territórios ocupados por povos indígenas na Bolívia.

Para tanto, percorreremos, além da presente introdução, os seguintes pontos: 2) Quem são os povos indígenas da América Latina e qual relação estabelecem com o território; 3) Breve histórico do tratamento dado aos territórios dos povos indígenas originários na Bolívia; 4) A Constituição do Estado Plurinacional da Bolívia e o tratamento dado aos territórios dos povos indígenas originários; e 5) Conclusão.

\section{QUEM SÃO OS POVOS INDÍGENAS DA AMÉRICA LATINA E QUAL RELAÇÃO ESTABELECEM COM O TERRITÓRIO}

Definir um conceito para "indígenas" ou "povos indígenas" é uma tarefa difícil que pode ser realizada a partir da adoção de critérios e visões distintas e envolver diversas áreas do conhecimento. Por isso, tal definição nunca será absoluta.

De acordo com Villares (2013, p. 28) os povos indígenas podem ser identificados a partir de alguns critérios, quais sejam: "i) as características físicas; ii) a autoidentificação iii) a identidade comunitária iv) a língua própria v) os costumes e tradições vi) a investigação de parentesco e laudo antropológico".

Cobo (1981 apud BARRIÉ, 2005, p. 62) afirma que os indígenas fazem parte de "setores distintos da sociedade que hoje prevalece no território americano ou em parte dele, e que possuem a determinação de desenvolver e de repassar às futuras gerações seus territórios e sua identidade étnica de acordo com sua configuração social originária", ou seja, considerando suas crenças, tradições e formas de organização.

Barrié (2005, p. 62) afirma que no âmbito do direito internacional a palavra "indígena" assume um significado preciso e faz referência aos "povos que foram colonizados, oprimidos ou conquistados e que resistem, pretendendo preservar ou recriar a sua cultura". Acrescenta ainda que cabe aos indígenas se definirem através da autodescrição ou da autoidentificação.

No âmbito normativo internacional, por sua vez, a Convenção nº 169 da Organização Internacional do Trabalho (OIT) que trata da proteção dos povos indígenas e tribais reconhece já na introdução e em consonância com as visões 
acima elencadas, a existência do instituto da autoidentidade indígena e tribal como fundamental para identificação de tais grupos. Sendo assim, não cabe a nenhum Estado ou grupo social negar a "condição" de indígena a quem assim se reconheça ou defina, bem como não cabe a atribuição de tal "condição" a quem assim não se identifique. A positivação e o reconhecimento do instituto da autoidentificação foi feliz e primordial, uma vez que não reduz o indígena a um estereótipo criado, justamente, por aqueles que por tantos anos os subjugaram. Ademais, não permite que haja um processo de etiquetação ou de rotulação dos povos indígenas, fato que poderia remeter a um caráter de objetificação de tais povos, atitude contrária não só as reivindicações por eles feitas como também aos direitos humanos.

A mesma Convenção no 169 da OIT, em seu artigo 10, trouxe a definição do que seriam povos tribais e povos indígenas, senão vejamos:

ARTIGO 10

1. A presente Convenção aplica-se a:

a) povos tribais em países independentes cujas condições sociais, culturais e econômicas os distingam de outros segmentos da comunidade nacional e cuja situação seja regida, total ou parcialmente, por seus próprios costumes ou tradições ou por uma legislação ou regulações especiais;

b) povos em países independentes considerados indígenas pelo fato de descenderem de populações que viviam no país ou região geográfica na qual o país estava inserido no momento da sua conquista ou colonização ou do estabelecimento de suas fronteiras atuais e que, independente de sua condição jurídica, mantêm algumas de suas próprias instituições sociais, econômicas, culturais e políticas ou todas elas.

2. A autoidentificação como indígena ou tribal deverá ser considerada um critério fundamental para a definição dos grupos aos quais se aplicam as disposições da presente Convenção.

3. A utilização do termo povos na presente Convenção não deverá ser interpretada no sentido de acarretar qualquer implicação no que se refere a direitos que possam ser conferidos no âmbito do Direito Internacional. (ORGANIZAÇÃO INTERNACIONAL DO TRABALHO, 2011, não paginado).

Cumpre esclarecer que é possível, ainda, a diferenciação entre os conceitos de indígenas, índios e povos indígenas, por exemplo. No entanto, não é nossa intenção realizar tal diferenciação. Da mesma forma, não pretendemos analisar detalhadamente as diferenças e particularidades existentes entre as próprias comunidades de povos indígenas.

Nos interessa destacar, uma vez que realizaremos o nosso estudo dentro do contexto boliviano, que é possível extrair, através da análise de distintos artigos da Constituição do Estado Plurinacional da Bolívia (2009), que é "nação" ou "povo 
indígena originário campesino" toda a coletividade humana que assim se autoidentifique cuja existência seja anterior a invasão colonial espanhola, que compartilhe identidade cultural, idioma, tradição histórica, instituições, território, organização ou instituições jurídicas, políticas, sociais e econômicas próprias e cosmovisão.

Por tudo exposto, considerando que o conceito de povos indígenas é aberto e suscetível a mudanças de acordo com a abordagem empregada, adotaremos um conceito geral e único para índios, indígenas e povos indígenas no âmbito latinoamericano, qual seja: são povos indígenas aqueles descendentes de populações que já se encontravam na América Latina quando da conquista e da colonização europeia, que possuem e compartilham de maneira comunitária e coletiva costumes e tradições próprias que se desenvolvem no âmbito de um mesmo território. Ademais, tais povos se autoidentificam como tal. Acrescentamos que nos parece não ser possível imaginar tais povos sem pensar em coletividade e em comunidade, por ser uma ideia que se desenvolve, justamente, no habitar e no lidar com a terra, no processo de ocupação e aproveitamento do território.

"Os povos indígenas são povos essencialmente coletivos" (BRANDÃO, 2015, p. 149). A ideia de coletividade na concepção indígena é ancestral e vital. Para tais povos, de forma geral, não só o território como também os meios de produção, os campos, as florestas e as águas pertencem à comunidade e são, portanto, de propriedade coletiva, ainda que haja, dentro de algumas comunidades indígenas, variações em relação ao cultivo e uso da terra. Inclusive, em algumas comunidades, para que o uso do solo possa ser feito é necessário pertencer à comunidade em questão. "De acordo com a cosmovisão indígena, a terra não pode ser vista como algo descontextualizado, sendo integrada por outros conceitos, como religião, cultura, história, política, economia." (MACEIRA, 2011, p. 316).

A terra não é apenas um elemento material tangível, mas é, principalmente, um elemento subjetivo e variante que assume um caráter transcendental. Por esse motivo, a ocupação do território se dá, tradicionalmente, sem a colocação de cercas ou em forma de loteamentos. A terra é ocupada e desenvolvida por todos que pertencem àquela comunidade de forma coletiva e livre. Os povos indígenas não reconhecem em sua tradição o conceito de propriedade privada territorial. A terra, 
tanto em sentido amplo, cósmico, como em sentido estrito, territorial, é de todos, não sendo possível que haja apropriação individual.

De acordo com Barre (1982 apud MACEIRA, 2011, p. 316, tradução nossa): "A terra constitui tanto a condição de segurança individual quanto de coesão do grupo ${ }^{16 "}$.

"O território indígena é o suporte material para as relações sociais, a cultura, as tradições e as crenças de cada comunidade indígena. A garantia da posse das terras indígenas tem valor de sobrevivência física e cultural de cada povo." (VILLARES 2013, p. 97).

Nesse contexto, importante analisar a figura da "Pachamama", que representa a divindade para os povos indígenas andinos e é proteção, fertilidade, abundância, generosidade e maturação dos cultivos. A palavra "pacha"tem origem na linguagem indígena "Quechua"e "Aymara "e significa terra em seu sentido amplo, ou seja, como cosmos, universo. A palavra "mama", de mesma origem, significa mãe. Sendo assim, "Pachamama" quer dizer "Mãe Terra". O conceito de "Pachamama", por sua vez, guarda uma estreita relação com a concepção de terra em sentido estrito, ou seja, como território e também com a riqueza que a terra produz, já que a economia dos povos originários se baseia na produção agrícola.

Portanto, a terra entendida como território se apresenta para os povos indígenas como local no qual, de maneira equilibrada, harmoniosa e sempre respeitando a "Pachamama", ocorrem os cultivos não apenas literais agrícolas como também figurados culturais. É no território que a identidade indígena, impregnada de tradições e crenças ancestrais, se desenvolve coletiva e comunitariamente. A relação indígena com o território é espiritual. Retirar de tais povos a possibilidade de se relacionar com o seu território em consonância com seus costumes é negar a sua identidade. Por sua vez, recusar a existência da identidade indígena, ou seja, a possibilidade de ser quem se é, é rejeitar a dignidade. Rejeitar a dignidade é ceifar a vida.

Nesse contexto, a relação que os povos indígenas desenvolvem com o território vai além da que os colonizadores e, modernamente, a sociedade atual

16 Traduzido do original: "la tierra contituye a la vez la condición de la seguridad individual y la cohesión de grupo". 
foram ou são capazes de manter. Como vimos, para os povos indígenas a importância da terra não está no valor de mercado que ela possui, mas sim na identidade construída naquele determinado e específico pedaço de chão, naquele território. A terra, tanto na concepção universal subjetiva como na concepção específica objetiva, é a mãe, é o local no qual ocorreu o nascimento, no qual viveram os antepassados, o chão no qual as atividades tradicionais que os conectam uns com os outros e com a natureza se desenvolvem, sendo o elo que une cada indígena e os transforma em comunidade. A terra é, em última instância, elemento de coesão e identidade, não sendo passível de nenhuma forma de apropriação exclusiva, individual.

Por sua vez, não só na realidade colonizadora e colonial, como também no âmbito da sociedade pós-colonial moderna, o território assume grande importância, ainda que sob enfoques completamente diferentes. O modo de organização do território em nossa sociedade se desenvolve com base no conceito de propriedade privada, na qual a posse, uso e exploração não são exercidos de forma coletiva. Além disso, a terra é vista, de maneira geral, não como um elemento formador da identidade social, mas sim como um bem que tem valor enquanto for capaz de produzir e, consequentemente, gerar lucros.

O pensamento de Maceira (2011, p. 317, tradução nossa) expõe acertadamente as diferenças existentes entre a importância assumida pela terra na cultura indígena e na cultura ocidental colonial e pós-colonial:

O ocidental quer mudar a natureza de acordo com seu próprio interesse, moldá-la às suas normas para fazê-la entrar em sua racionalidade. 0 indígena, ao contrário, não tenta dominá-la e sim adaptar-se à ela, permeando suas leis e vivendo em harmonia com elas, sem tentar impor nada ${ }^{17}$.

Quando chegaram ao "Novo Mundo", segundo Sulstrang (1977), os europeus consideraram, em mais um exemplo de comportamento etnocentrista, que as terras não eram adequadamente utilizadas pelos povos indígenas e que deveriam eles,

\footnotetext{
17 Traduzido do original: "El occidental quiere cambiar la naturaleza segúnsu próprio interés, plegarla a sus normas para hacerla entrar em suracionalidad. El indígena, por elcontrario, no trata de dominarla, sino que se adapta a ella, se impregna de sus leyes y vive em armonia com ellassin tratar de imponerleotras."
} 
europeus superiores, utilizar a mão de obra indígena para dar a destinação correta a tais terras, além de passarem a ser proprietários das mesmas.

Acrescentamos ainda que a propriedade, notadamente a propriedade territorial, sempre foi tida como direito primordial a ser conservado tanto nas sociedades europeias e norte-americanas, como nas sociedades coloniais e póscoloniais de caráter liberal-conservador da América Latina. Tal direito sempre se mostrou como legitimador do exercício de outros, especificamente os políticos. Por muitas vezes a propriedade da terra foi condição para que o indivíduo fosse sujeito de direitos, direta ou indiretamente, uma vez que a dicotomia proprietários/não proprietários, em grande medida, é um movimento cíclico que pautou e continua pautando as relações de poder estabelecidas na região, na qual os não proprietários, por ostentarem tal condição, são dominados pelos que são proprietários. Por esse motivo, o reconhecimento do caráter coletivo da terra era e continua sendo uma dupla ameaça aos interesses das classes dominantes, uma vez que conservar os territórios indígenas com caráter coletivo importa em diminuição de lucros e frustraçãodos interesses individuais das classes dominantes locais e, ao mesmo tempo, dotar os povos indígenas de poder não é nada útil aos interesses do mercado internacional.

Apesar de todas as considerações feitas até aqui, o constitucionalismo latinoamericano, ainda que paulatinamente e não de maneira perfeita, vem se desenvolvendo no sentido de reconhecer os direitos dos povos indígenas, inclusive no que diz respeito às terras por eles originalmente ocupadas. Segundo Yrigoyen Fajardo (2012), o terceiro ciclo do constitucionalismo plurinacional que teve seu início nos anos 2000, ou seja, já no século XXI, traz grandes avanços nesse sentido, tendo como um de seus marcos o processo constituinte boliviano que desembocou na Constituição do Estado Plurinacional da Bolívia, que passaremos a analisar exclusivamente no que diz respeito ao tratamento dado às terras indígenas.

\section{BREVE HISTÓRICO DO TRATAMENTO DADO AOS TERRITÓRIOS DOS POVOS INDÍGENAS ORIGINÁRIOS NA BOLÍVIA}

A Bolívia contou, a partir da sua independência e com o advento da República, com diversas Constituições que, por sua vez, foram reformadas inúmeras 
vezes. A mais recente Constituição boliviana e que se encontra em vigor atualmente é a Constituição Política do Estado Plurinacional da Bolívia, datada de 2009 e que será fruto de nossa análise mais detalhada adiante. (BOLÍVIA, 2009).

No entanto, as constituições bolivianas nem sempre reconheceram o Estado como plurinacional ou encamparam os direitos dos povos indígenas. A palavra propriedade, no entanto, aparece já na Constituição de 1826 como direito assegurado aos "bolivianos" (BOLÍVIA, 1826). "Em sua Carta de 1826, Simón Bolivar perfilou uma sociedade senhorial, ao estilo das que se viam na Europa-liberal do novo regime instaurado pela Revolução Francesa." (INSTITUTO NACIONAL DE REFORMA AGRÁRIA, 2008, p. 40).

A primeira vez que a palavra "indígena" foi utilizada em uma Constituição boliviana foi na de 1938, na qual foi garantida a existência legal das comunidades indígenas e normatizado que a legislação indígena e agrária seria sancionada tendo em conta as características de diferentes regiões do país (arts. 165 e 166). A mesma constituição previu que a propriedade privada deveria cumprir sua função social e poderia ser expropriada (art. 17). (BOLÍVIA, 1938).

Posteriormente, a Constituição de 1967, que contou com alterações nos anos de 1994, 1995, 2004 e 2005, inovou e reconheceu, pela primeira vez na história constitucional boliviana, a existência das ditas "Terras Comunitárias de Origem" (TCO) (art. 171, I). Além disso, houve o reconhecimento da personalidade jurídica das comunidades indígenas e campesinas (art. 171, II). Desde então, passou-se a se falar em propriedade privada não só individual, mas também coletiva, como um direito fundamental condicionado ao cumprimento da função social (art.6,i). As terras eram tidas como de domínio originário da nação, cabendo ao Estado a distribuição, reagrupamento e redistribuição da propriedade agrária de acordo com as necessidades econômico-sociais e o desenvolvimento rural (art. 165). Ademais, o trabalho passou a ser fundamento da propriedade agrária (art. 166). A Constituição passou a prever o direito de proteção e respeito aos direitos relativos às terras comunitárias de origem e a garantia do uso e aproveitamento sustentável dos recursos naturais, da identidade, valores, línguas, costumes e instituições dos povos indígenas (art. 171, I). (BOLÍVIA, 2005). 
A questão das terras originariamente ocupadas pelos índios na Bolívia, assim como em toda a América Latina, sempre foi um tema muito delicado e central, devido ao seu caráter estratégico na perpetração e perpetuação do poder. Ainda na época colonial o rei Felipe II reconheceu o direito das comunidades indígenas a desfrutarem de sua terra de maneira comunal. No entanto, a propriedade das terras continuava sendo da Coroa Espanhola.Os espanhóis recebiam da Coroa Espanhola a propriedade de extensões de terra, que foram chamadas de "haciendas".

Com o advento da República, o sistema de "haciendas" e de terras comunais passou a coexistir.

Entretanto, os povos indígenas passaram a ter que trabalhar nessas "haciendas" na qualidade de colonos ou campesinos. O trabalho era feito durante quatro dias da semana. Em troca, recebiam apenas $200 \mathrm{~m}^{2}$ de terra para proveito próprio e mais nenhuma remuneração. Sobre as terras recebidas incidia, ainda, um tributo a ser pago pelos indígenas.

A partir de então, diversas e variadas foram as medidas legais que deram início a um movimento que acabou por inviabilizar e sufocar o cultivo comunal da terra em detrimento do modelo de "haciendas". Entre tais medidas, a necessidade de pagamento por parte dos indígenas para que fosse obtido o título de propriedade da terra e a política de "Revisitas". Assim nasceram os latifúndios na Bolívia.

Frente a tal situação, tiveram início alguns levantes indígenas que foram abafados e reprimidos de forma violenta, mas não foram mortos. Porém, em 1952, veio à tona uma Revolução Popular que acabou desembocando na reforma agrária que teve seu marco inicial em 1953. As bases da reforma agrária boliviana se fixaram na ideia de que a propriedade da terra pressupunha o trabalho. A partir de então, tornou a ganhar espaço a ideia de "propriedade comunitária" e a produção coletiva. No entanto, o modelo adotado para a realização da reforma agrária acabou, mais uma vez, beneficiando menos os povos indígenas cultivadores da terra coletiva, e mais aos médios e grandes proprietários. "Em 1953, das 11.000 comunidades existentes, restavam apenas 3.783." (INSTITUTO NACIONAL DE REFORMA AGRÁRIA, 2008, p. 40).

Nesse contexto, surgiu a Lei no 1715 do Instituto Nacional de Reforma Agrária (INRA) destinada a reorientar o processo agrário na perspectiva dos povos 
indígenas. Diante da insuficiência de tal lei, em 2006 foi promulgada a Lei no 3545, Lei da Recondução Comunitária da Reforma Agrária Modificatória da Lei de Serviço Nacional de Reforma Agrária. (BOLÍVIA, 2006).

Sendo assim, podemos dizer que o processo de reforma agrária na Bolívia é o principal instrumento de redistribuição de terras indígenas e se caracterizou pela ocorrência de duas etapas importantes: a reforma agrária de 1953-1992 e a de 1996-2006. De 2006 para cá é inaugurada uma nova fase do processo de reforma agrária. Tal fase vem se desenvolvendo sob a égide da Constituição do Estado Plurinacional da Bolívia. Passaremos, então, a abordar de que maneira a Constituição Boliviana de 2009, considerada um marco do novo constitucionalismo latinoamericano, trata a questão da propriedade das terras indígenas.

\section{A CONSTITUIÇÃO DO ESTADO PURINACIONAL DA BOLÍVIA E O TRATAMENTO DADO AOS TERRITÓRIOS DOS POVOS INDÍGENAS ORIGINÁRIOS}

O próprio nome Constituição do Estado Plurinacional da Bolívia já demonstra, por si só, a tentativa de realização de um Estado plurinacional, ou seja, que abarque também os povos indígenas não só como povos de "cultura diversa, mas também como sujeitos políticos coletivos, com o direito de definir o seu destino e participar dos pactos do Estado." (BRAGATO; FERNANDES, 2015, p. 33). Nesse sentido, a supracitada Constituição dedicou um capítulo exclusivo para os "Direitos das Nações e Povos Indígenas Originários Campesinos".

No entanto, não nos aprofundaremos em todos os âmbitos de proteção e participação indígenas abarcados em tal documento, mas tão somente naqueles que têm relação direta com a questão da propriedade dos territórios originalmente ocupados pelos povos indígenas.

A Constituição Boliviana parece adotar o entendimento, que também compartilhamos, de que o território indígena não é pura e simplesmente a terra em seu caráter material, mas também a área de produção, de aproveitamento, conservação dos recursos naturais e espaço no qual são desenvolvidas as tradições social, espiritual e cultural, ou seja, espaço no qual é trabalhada a própria identidade indígena (art. 403). Os territórios indígenas originários são, ainda, expressamente 
entendidos como integrantes da organização territorial boliviana. (art.269, I). (BOLÍVIA, 2009).

Partindo desse entendimento, o domínio territorial a ser exercido pelos povos indígenas é tido como ancestral. (art. $2^{\circ}$ ). Daí, a ancestralidade é o que garante a consolidação das entidades territoriais, sendo um direito, bem como a titularidade coletiva de terras (art. 30, II, 4 e 6).Faz parte da integração do território indígena o direito à terra, ao uso e ao aproveitamento exclusivo dos recursos naturais renováveis e a gestão territorial autônoma (art. 30, II, 17) (BOLÍVIA, 2009).

O Estado passa a reconhecer, proteger e a garantir a propriedade comunitária ou coletiva, que compreende o "Território Indígena Originário Campesino" (TIOC) no lugar do antigo instituto das "Terras Comunitárias de Origem" (TOC). Tal propriedade, em seu caráter coletivo, é indivisível, imprescritível, impenhorável, inalienável e irreversível, não incidindo, ainda, o pagamento de imposto (art. 394, III) (BOLÍVIA, 2009).

Quando da proteção da propriedade, a Constituição faz referência não apenas à propriedade privada, nos moldes que conhecemos e que costuma ser mais comumente encontrada nas Constituições dos países latino-americanos, mas também à propriedade coletiva, fazendo clara alusão a forma de propriedade desenvolvida no âmbito das comunidades indígenas (art. 56, I). Em ambos os casos, a propriedade fica condicionada à observância da função social ou função econômico social. A função social corresponde ao aproveitamento sustentável da terra por parte dos povos e comunidades indígenas originárias campesinas, assim como a que se realiza em pequenas propriedades, e constitui a fonte de subsistência, de bem-estar e de desenvolvimento sociocultural de seus titulares, segundo as normas das comunidades. A função econômicosocial, por sua vez, corresponde ao emprego sustentável da terra no desenvolvimento de atividade produtivas, em benefício da sociedade, do interesse coletivo e de seu proprietário (art. 397) (BOLÍVIA, 2009).

Os "Territórios Indígenas Originários Campesinos" (TIOC) são parte integrante da organização territorial, sua criação, modificação e delimitação considera a própria vontade dos habitantes, nos termos da constituição e da lei. (art. 269, II). No entanto, se quando da criação de "Território Indígena Originário Campesino" houver conflito com área não indígena, haverá procedimentos perante a 
Assembléia Legislativa Plurinacional ou perante o Governo Municipal (art. 293, II e 295, I). (BOLÍVIA, 2009).

Dentro do âmbito dos territórios indígenas haverá o autogoverno, devendo vigorar as tradições, costumes e a própria organização dos povos indígenas, podendo, inclusive, ocorrer a elaboração de um estatuto que deverá estar em harmonia com as disposições legislativas e constitucionais. $\mathrm{O}$ território reconhecidamente indígena assume uma série de competências quanto a elaboração de planos de ordenamento territorial e de uso do solo, planificação e gestão da ocupação territorial. Inclusive, deverá haver consulta sobre a exploração de recursos naturais quando tais recursos se encontrem em territórios indígena (art. 403).Ainda em relação aos recursos naturais não renováveis, terão os indígenas direito a participarem dos resultados da exploração de tais recursos quando realizada em seu território (art. 30,II,15 e 16). Além disso, é assegurado ao povo boliviano acesso equitativo ao que for proveniente do aproveitamento de todos os recursos naturais, sendo atribuída uma participação prioritária aos territórios onde se encontrem tais recursos e aos povos indígenas. (art.353). (BOLÍVIA, 2009).

Quando os territórios indígenas estiverem localizados em áreas protegidas, será realizada uma gestão compartilhada do território, com sujeição às normas e procedimentos próprios da nação e povos indígenas (art. 385, 2). Ademais, quando as comunidades estiverem situadas dentro de áreas florestais, a titularidade do direito exclusivo do seu aproveitamento e gestão, nos termos da lei, caberá à comunidade indígena (art.388) (BOLÍVIA, 2009).

Há, ainda, previsão de que aos povos indígenas em situação de isolamento voluntário serão garantidos o direito de proteção e serão respeitadas a forma de vida individual e coletiva (art. 31) (BOLÍVIA, 2009).

Por fim, no que diz respeito a assuntos tocantes à reforma agrária, as comunidades poderão ser reconhecidas considerando a complementariedade entre direitos coletivos e individuais, sendo colocados a salvo os direitos de proprietários particulares cujos prédios se encontrem localizados no interior dos "Territórios Indígenas Originariamente Campesinos" (art. 394). Outros dois pontos importantes são o de que fica proibido o latifúndio, uma vez que em nenhum caso a superfície da propriedade poderá exceder os 5.000 hectares. Ademais, a terra deverá ser 
produtiva, cumprir com a função econômico social, não podendo adotar um sistema de trabalho de servidão ou de escravidão (art. 398). As terras fiscais, fruto de antigos processos no tratamento da terra implementados na Bolívia, serão fornecidas a indígenas originários campesinos, comunidades interculturais originárias, afrobolivianos e comunidades campesinas que não as possuam, ou as possuam de maneira insuficiente, sendo possível tais terras serem, inclusive, titularizadas por mulheres, independentemente do estado civil (art. 395) (BOLÍVIA, 2009).

\section{CONCLUSÃO}

Os povos indígenas da América Latina, desde o período de conquista e colonização até a atualidade, sofreram e vêm sofrendo o que seja, talvez, uma das maiores crueldades que um povo pode experimentar: morrer e continuar vivendo. Isso porque, o etnocentrismo europeu e a perpetuação de uma elite de caráter majoritariamente liberal-conservador, individualista e refém do mercado, não permitiram que o "diferente", sustentável e coletivo se desenvolvesse.

Antes da chegada do "homem branco" os indígenas já se relacionavam com a terra a partir de dois aspectos: um universal, subjetivo, figurado, e outro específico, objetivo, territorial. Nas duas concepções a relação era travada de forma comunitária e em harmonia com a natureza. Para eles a terra é a mãe, é quem traz à vida, e o território é o pedaço de terra no qual a vida acontece, sendo o elo que une cada índio e os transforma em um povo.

Portanto, negar aos povos indígenas o direito de acesso aos territórios ancestralmente ocupados por eles e por seus antepassados é negar a identidade, é ceifar a vida.

Felizmente, as recentes ondas de reformas constitucionais que vêm acontecendo na América Latina têm assumido uma nova roupagem, e são não apenas no sentido de reconhecer a existência dos povos indígenas, como também no de reconhecer o direito ao exercício da identidade de tais povos.

A Constituição do Estado Plurinacional da Bolívia se distingue por ser um giro paradigmático na teoria da Constituição, uma vez que procura internalizar o conhecimento e a cosmovisão indígena. 
Destacamos, então, o ponto que diz respeito ao tratamento dado aos territórios originalmente ocupados pelos povos indígenas, uma vez que entendemos ser tal questão crucial para a preservação da identidade e da vida digna de tais povos. Nessa matéria, a Constituição boliviana positivou a importância da terra não apenas sob o ponto de vista objetivo e territorial, como também sob a ótica subjetiva e universal, incorporando ao texto constitucional a cosmovisão indígena.

Ainda, o reconhecimento da existência do "Território Indígena Originário Campesino" (TIOC) como parte da organização territorial do país demonstrou mais um passo rumo a real efetivação da noção de que os povos indígenas, com seus territórios, fazem parte da Bolívia e não estão mais à margem da sociedade.

Outro ponto que merece realce é o que diz respeito ao fato de que a propriedade da terra pelos povos indígenas poderá ser exercida de maneira comunitária, isto é, de acordo com suas tradições e cultura, sem a necessidade que haja uma adaptação forçada ao modelo de exploração territorial baseado na propriedade privada.

Ressalte-se, ainda, o fato de que ficaram os povos indígenas responsáveis pela gestão de seus territórios, bem como pela elaboração de planos de ordenamento territorial e uso do solo e também pela manifestação de vontade quanto à exploração dos recursos naturais que ali se encontrem.

De forma geral, as novas disposições constitucionais trazem a possibilidade que a relação desenvolvida pelos povos indígenas com o território se dê em harmonia e em equilíbrio com a "Mãe Terra", elemento central e vital da cultura indígena.

Sendo assim, a Constituição do Estado Plurinacional da Bolívia, ao menos como documento formal, é ousada e, de fato, promissora no que diz respeito ao tratamento dado às terras indígenas originárias. No entanto, não podemos esquecer que a realização ou não do que resta garantido no texto constitucional depende da maneira com que os poderes instituídos irão lidar com a questão. Infelizmente, na tradição latino-americana, as classes dominantes acabam se valendo da forma com que os poderes são organizados para impor sua vontade e manejar os institutos que deveriam assegurar direitos para manter os grupos minoritários fora do jogo do poder, ou seja, na posição de meros espectadores. 
Nesse contexto, a Bolívia vem atravessando uma severa crise política ${ }^{18}$ que culminou, em 2019, na renúncia do presidente Evo Morales, que cumpria o seu quarto mandato, e que em seu primeiro mandato viu nascer a Constituição de 2009. Um dos momentos simbólicos do embate entre apoiadores do agora ex-presidente e seus opositores envolveu, justamente, o emblema dos povos indígenas da região dos Andes: a whiphala ${ }^{19}$, que é também um dos símbolos oficiais do Estado Plurinacional da Bolívia, tendo sido assim oficializado na Constituição de 2009.

Enquanto os apoiadores de Evo, que são principalmente camponeses, a levantavam em sinal de resistência, opositores a queimavam pelas ruas de La Paz. Tal ato é emblemático principalmente porque a whipala está diretamente relacionada com a identificação cultural dos povos andinos e representa a unidade, a solidariedade e a harmonia entre as diferentes etnias indígenas do Império Inca.

Dessa forma, para além da insatisfação de alguns setores da sociedade com o governo de Evo Morales, é possível perceber, em alguma medida, que há, igualmente, a externalização de um rechaço ao protagonismo indígena e um movimento de polarização entre indígenas e brancos e entre as classes média e baixa, que é fruto, como já vimos, de uma crise que é profunda e histórica.

Em que pese ser possível e saudável tecer críticas aos inúmeros governos de Evo Morales, é inegável que se tratou do primeiro presidente indígena - aymara - de uma nação que é - também - majoritariamente indígena e que, pela primeira vez

\footnotetext{
${ }^{18}$ Em fevereiro de 2016 ocorreu um referendo para decidir pela possibilidade do então presidente Evo Morales participar das eleições por meio da qual poderia vir a ser reeleito para cumprir seu quarto mandato. $\mathrm{O}$ resultado do referendo foi negativo. No entanto, Evo Morales, após recorrer ao Tribunal Constitucional da Bolívia, conseguiu permissão para participar das eleições presidenciais de outubro de 2019. Após a realização das eleições, antes mesmo da divulgação oficial do resultado, e diante de uma possível vitória de Evo Morales, os opositores, simpatizantes do também candidato Carlos Mesa, foram às ruas para denunciar uma fraude na apuração dos resultados eleitorais. Após alguns dias de indefinição, Evo Morales foi, então, oficialmente declarado eleito para cumprir seu quarto mandato. No entanto, a Organização dos Estados Americanos (OEA) e o governo da Bolívia anunciaram que o processo eleitoral seria auditado. Diante dos fatos, parte da população começou a se movimentar no sentido de pedir que Evo renunciasse e que novas eleições fossem realizadas. Policiais decidiram que não iriam conter os protestos, e a OEA concluiu que houve fraude nas eleições. Após convocar novas eleições, Evo Morales e o vice-presidente Álvaro Garcia Linera, renunciaram aos cargos, fato que provocou, então, uma onda de protestos que culminou nos embates entre opositores e apoiadores de Evo Morales.

${ }^{19} \mathrm{~A}$ whipala pode ser definida como "um pedaço de tecido quadrado e multicolorido, como um xadrez pintado a sete cores. Assim é a whipala, bandeira típica dos povos andinos nas cores vermelha, amarela, branca, verde, azul e violeta, que, no idioma aimará (da etnia homônima), significa "objeto flexível, ondulante e quadriculado", ou ainda "felicidade ou triunfo que ondula ao vento".
} 
após séculos de opressão colonial, trouxe os povos indígenas para dentro da Constituição respeitando sua cosmovisão.

Em uma democracia frágil como é a boliviana, e considerando a afronta que a Constituição do Estado Plurinacional da Bolívia pode representar para os interesses do capital nacional e estrangeiro, mostra-se ainda mais importante assegurar que os avanços empreendidos não só não se percam, como se efetivem.

\section{REFERÊNCIAS}

AQUINO, Rubim Santos Leão de; LEMOS, Nivaldo Jesus Freitas de; LOPES, Oscar Guilherme Pahl Campos. História das Sociedades Americanas. 4. ed. Rio de Janeiro: Ao Livro Técnico, 2005.

BARRIÉ, Cletus Gregor. La Cuestión territorial de los pueblos indígenas em la perspectiva latino-americana. Caracas: Instituto Latino americano de Investigaciones Sociales (ILDIS), 2005. Disponível em: http://saludpublica.bvsp.org.bo/.../bvsp/.../territorio-pueblosindigenas....\%20Em\%C2\%A0cache\%20Similares. Acessado em: 02 out. 2019.

BARRIÉ, Cletus Gregor. Pueblos indígenas y derechos constitucionales em América Latina: um panorama. Bolívia: Comisión Nacional para el Desarollo de los Pueblos Indígenas: Gobierno de México: AbyaYala: Banco Mundial, 2003.

BOLÍVIA. Constitución política de 1826, 19 de noviembre de 1826. Primera Constitución Política de la República Boliviana. La Paz: Congreso Jeneral constituyente de la República Boliviana, 1826. Disponível em: http://comisiondeconstitucion2002-2003.awardspace.com/cpehistoria/cpe_1826.htm Acesso em: 28 out. 2019.

BOLÍVIA. Constitución política de 1938, 30 de octubre de 1938. La Paz: Presidencia Constitucional de la República, 1938. Disponível em: https://www.lexivox.org/norms/BO-CPE-19381020.xhtml. Acesso em: 28 out. 2019.

BOLÍVIA. Constitución Política del Estado. 2 de febrero de 1967. Con reformas de 1994, texto concordado de 1995, y reformas de 2002, 2004 y 2005. La Paz: Presidencia Constitucional de la República, 2005. Disponível em: http://pdba.georgetown.edu/Constitutions/Bolivia/consboliv2005.html. Acesso em 21 jun. 2019.

BOLÍVIA. Constituição Política do Estado (CPE). La Paz: Assembleia Constituyente: Honorável Congresso Nacional, 2009. Disponível em: http://pdba.georgetown.edu/Constitutions/Bolivia/bolivia09.html. Acesso em: 28 out. 2019. 
BOLÍVIA. Lei no 3545, de 29 de novembro de 2006. Lei de Recondução Comunitária da Reforma Agrária. La Paz: Presidencia Constitucional De La Republica. Disponível em:http://www.ftierra.org/index.php/tierra-y-territorio/106-ley-n-3545-dereconduccion-comunitaria-de-la-reforma-agraria-modifica-la-ley-n-1715-inra. Acesso em: 28 out. 2019.

BRAGATO, Fernanda Frizzo; FERNANDES, Karina Macedo. Da colonialidade do poder à descolonialidade como horizonte de afirmação dos Direitos Humanos no âmbito do constitucionalismo Latino-Americano. Revista Culturas Jurídicas, [S.I.], v. 2, n. 4, p. $15-41,2016$.

BRANDÃO, Pedro. O novo constitucionalismo Pluralista Latino-Americano. 2. ed. Rio de Janeiro: Lumen Juris, 2015.

CUNHA, Manuela Carneiro da. Índios no Brasil: História, Direitos e Cidadania. São Paulo: Companhia das Letras, 2012.

GALEANO, Eduardo. As Veias Abertas da América Latina. 44. ed. Rio de Janeiro: Paz e Terra, 2004.

GARGARELLA, Roberto. La Sala de máquinas de la Constitución: Dos siglos de constitucionalismo em América Latina (1810-2010). Buenos Aires: Katz, 2014.

INSTITUTO NACIONAL DE REFORMA AGRÁRIA. Breve Historiadel Reparto de Tierras em Bolivia: De latitulación colonial la Reconducción Comunitária de la Reforma Agraria:certezas y proyecciones. La Paz: INRA, 2008. Disponível em: http://www.inra.gob.bo/InraPb/upload/Brevehistoria2008.pdf. Acesso em: 10 out. 2019.

MACEIRA, Malena Rocío. El Estado argentino y los pueblos originários. El respeto por la propriedade comunitaria. Revista Electrónica del Instituto de Investigaciones "Ambrosio L. Gioja", [S.I.], año 5, número especial, p. 312-322, 2011. Disponível em: http://misionlatinoamericana.webnode.com/news/propiedadcomunitaria-pueblos-originarios-en-argentina-fuente-www-derecho-uba-ar-re-/. Acesso em: 28 out. 2016.

MOTA, Myriam Brecho; BRAICK, Patrícia Ramos. História: Das Cavernas ao Terceiro Milênio. 2 ed. São Paulo: Moderna, 2002.

ORGANIZAÇÃO INTERNACIONAL DO TRABALHO. Convenção no 169 sobre povos indígenas e tribais. Brasília, DF: OIT, 2011. Disponível em:

http://portal.iphan.gov.br/uploads/ckfinder/arquivos/Convencao_169_OIT.pdf. Acesso em: 28 out. 2016.

SULSTRANG, A. Informe de lacomisión exploradora del Chaco. Buenos Aires: Eudesa, 1977.

VILLARES, Luiz Fernando. Direito e Povos Indígenas. 2. ed. Curitiba: Juruá, 2013. 
YRIGOYEN FAJARDO, Raquel Zonia. El horizonte del constitucionalismo pluralista: del multiculturalismo a ladescolonización. In: GRAVITO, César Roberto (comp.). El derecho em América Latina: um mapa para el pensamento jurídico delsiglo XXI. Buenos Aires: Siglo Veintiuno, 2011. p. 139-184.

YRIGOYEN FAJARDO, Raquel. El pluralismo jurídico en la historia constitucional latinoamericana: de la sujecion a la descolonizacón. Lima: Instituto Internacional de Derecho y Sociedad, 2012.

Recebido em 27/02/2020.

Aceito em 27/03/2020. 